\title{
Dignity and Death : Psychological well being in death
}

\author{
Om Prakash Singh \\ Department of Psychiatry, N.R.S. Medical College and Hospital, Kolkata
}

Dignity in Mental Health is the theme of the World Mental Health day 2015. While talking of dignity for mentally ill persons another thought which comes to mind is dignity of dying. Mario Puzo In Godfather describes the death of Godfather at home in garden with bright sunlight and playing children around him saying "life is beautiful"; many of us will like this kind of death but we are condemned to die in ICU settings hooked with all kind of life support and all kind of tubes in body, with masked doctors as caregiver and no loved one at sight. This scenario is raising whole lot of questions regarding end of life care provided by health care delivery system .

In ICU setting there is terminology of "greenhouse effect". Like plants in the winter, they cannot survive outside of the life-sustaining greenhouse of the ICU. They are often consigned for weeks or even months to a sort of medical purgatory, attached by tubes in their tracheas to ventilators, with catheters protruding from their necks, chests, abdomens or bladders. When awake they are in constant discomfort, chronically deprived of sleep, and stripped of any dignity, so we often sedate them to the point that they are no longer in communication with their environment ${ }^{(1)}$.

Recent book by Atul, a neurosurgeon has raised these questions and people are talking about reevaluation of end of life care ${ }^{(2)}$. As the internist and critical care specialist fights for every breadth of the patient,it compromises the quality of life and it is sometimes referred as "prolongation of death than prolongation of life".

Landmark study at John Hopkins by Gallo has found that doctors like to die differently and they do not want life prolonging procedures to be done for them but they want to die at home ${ }^{(3,4)}$. This paradox negates a basic principle that you should do to your patients which you will like to be done for yourself.
With health industrial complex reaping profits, doctor as well as family members become victim of the system.However, rising costs of terminal care amounting 2.3 trillion dollars for America alone is forcing a relook into this matter.

Another issue becoming important is doctors talking about death to admitted patients. This has raised issues of skill and compensation for the time spent and Obama's Death Panel is talking about payment by insurance companies for time spent talking about death.

Closer home, there are other cultural issues which forces the family members to put the terminal patients for hospital admissions, requirement of Death certificate being one. Hospitals often discharge patients or threaten to discharge patients for whom they do not get consent for ventilator or other life saving procedures. Wanting to do best for their dear ones and fear of criticism by relatives also force them to agree to "everything" which could be done robbing the patient even a chance of dignified death. Doctors are fearful to discuss these issues due to fear of distrust and afraid of role reversal.

We need to have a relook on this issues and also regarding increasing skills for near death communication of doctors; Psychiatristshave arole to play in educating other doctors.

\section{REFERENCES}

1. Breslow Jason, Prolonging life or prolonging death? Two doctors on caring for the critically sick, Frontline February 13,2015

2. GawandeAtul, Being MortalMedicine and What Matters in the End

3. Gallo, JJ et al, What do physicians want and do they express their wishes to others? Journal of American Geriatrics Society 51(7), 961-969. 2003

4. Straton JB, Wang N-Y et al, Physical functioning, depression and preferences for treatment at the end of life : The John Hopkins Precursors Study. JAGS 52(4), 577-582. 2004 